\title{
Evaluating the logic of perspective-taking experiments
}

\author{
Zsófia Virányi • Friederike Range
}

Published online: 20 July 2011

(C) Psychonomic Society, Inc. 2011

\begin{abstract}
In their recent study, Udell, Dorey, and Wynne (in press)[COMP: Ref. is LBE0034. Will have to be updated to (2011) here and in LBE0038, once page nos. are available.] showed that in a begging task, at least in some conditions, dogs as well as wolves preferentially approached a human partner who could see them in contrast to one whose eyes were occluded, and Udell et al. concluded that this success was dependent on the subjects' experiences with the specific occluder used. Here we argue, however, that since both partners expressed similar attentiveness towards the subjects by calling their names, Udell and colleagues' conclusion does not refer to the sensitivity of canines to others' attentiveness, but instead reflects the fact that the animals obeyed a familiar command better in a familiar context than in an unfamiliar one. Moreover, in contrast to Udell et al.'s conclusion, we believe that their data demonstrate that pet dogs can generalize the use of the visibility of human eyes to novel situations, showing a preference towards an attentive partner even if the eyes of the other partner are occluded in a novel way (e.g., having a bucket on his or her head). Finally, after presenting alternative interpretations of the results of the wolves tested by Udell and colleagues, we
\end{abstract}

Z. Virányi $\cdot F$. Range $(\bowtie)$

Department of Cognitive Biology, University of Vienna,

Vienna, Austria

e-mail: friederike.range@univie.ac.at

Z. Virányi $\cdot F$. Range

Clever Dog Lab,

Vienna, Austria

Z. Virányi $\cdot F$. Range

Wolf Science Center,

Ernstbrunn, Austria conclude that there is no evidence that wolves are sensitive to the attentional states of humans.

Keywords Comparative cognition $\cdot$ Wolf $\cdot$ Dog

The begging task has been designed to test whether animals are sensitive to the attentional states of others, based on behavioural cues: that is, whether they differentiate between partners whose eyes either are or are not visible (Virányi, Range \& Huber, 2009). Accordingly, begging preferentially from an attentive in contrast to an inattentive partner is thought to reflect the ability to recognise that the attentive partner is in a position to perceive the beggar's visual signals and thus to provide food, whereas the inattentive partner, whose eyes are invisible, will miss the relevant signals and ignore the beggar's request (Gácsi, Miklósi, Varga, Topál \& Csányi, 2004; Povinelli \& Eddy, 1996). In order to receive a share of food, the beggar needs to initiate communication, either by using visual signals towards a partner who is looking at the subject or by using acoustic or tactile attention-getting signals, in the case that the partner is not attending to the beggar (Theall \& Povinelli, 1999). When examining whether the subject recognises who can see her and who cannot, it is thus important that the partners not provide additional cues that might indicate their attentiveness, as this is likely to render the visibility of the eyes an inconsequential predictor of attention. For example, you probably have experienced at one point being addressed by a colleague working on her computer when the two of you share an office, or of having been called to a gate at an airport by a loudspeaker; in both examples, you attended and were engaged in communication without being looked at, or even seen. You can recognise that a partner is attending to you even if the partner is not visually orienting towards you. When somebody calls your name 
and/or there is no other potential addressee around, you usually infer that the speaker's attention is directed at you, independent of her visual orientation (directed at either the monitor or the microphone, in our above examples). Dogs are also capable of making such inferences, as demonstrated by an obedience task (Virányi, Topál, Gácsi, Miklósi \& Csányi, 2004) in which dogs did not obey the "Down!" command when the owner delivered it repeatedly while turning towards another partner in a triadic situation. However, the dogs did lie down after hearing the same command and their name, if there was no one else in the focus of their owner's visual attention.

In Udell et al. (in press), both the "attentive" and "inattentive" human partners simultaneously called the subject's name and repeatedly delivered the command "Come!" while offering food in their hands. By initiating communication in this way, the two partners clearly expressed that they knew about the presence of the subject and showed similar attentiveness towards it. In addition to this, their visual access to the subject was systematically manipulated. If a subject paid more attention to the verbal and behavioural rather than to the visual cues of attentiveness, the subject would have no reason to discriminate between the two partners in such a situation. Similarly, there would be no need to differentiate between the two partners if the subject did not respond to the visibility of its partner's eyes, but rather evaluated their attention at the cognitive level, taking all verbal and behavioural cues as well as the absence of other animals into account. Such a confusing demonstration of attentional signals given by the partners is in contrast with the principle logic of the begging task, which should provide a choice between a clearly attentive and a clearly inattentive partner, which might explain why subjects failed to differentiate between two partners who called them in a similar way.

Nevertheless, Udell et al. (in press) found that some experimental groups differentiated between the two partners by preferentially approaching the seeing experimenter in those conditions in which one of the two partners called them in a manner familiar from their everyday experiences. Due to the above-mentioned experimental procedure, however, we argue that the differences across conditions result from the animals' enhanced obedience to the "Come!" command in the familiar rather than the unfamiliar context, instead of reflecting their sensitivity to others' attentiveness when seeing a familiar occluder, as suggested by the authors. Udell and colleagues argued that "domestic dogs and other socialized canids are not taking the mental perspective of the seeing or blind individual, but instead making a discriminative choice based on past reinforcement histories, in which certain human actions or orientations served as predictors of reinforcement upon approach" ( $\mathrm{p}$. xxx).[COMP: Insert pg no. when available] We agree completely with this second alternative, but doubt that their conditions using a familiar occluder would have had the potential to test for the animals' perspective-taking ability. In our view, instead of testing sensitivity to others' attentiveness, Udell and colleagues created an obedience task, due to the calling behaviour of the two partners. In this task, they tested which of two partners the subjects would obey more frequently on command to approach for food. They provided the subjects with a choice of two partners who were presented in eight different conditions, each of which was either familiar or novel to the subjects with respect to their former training history (e.g., each subject had regularly met a human facing the subject, calling its name, giving the "Come!" command, and offering food, but the subject would have no experience of a human with a bucket over his or her head so that the eyes were not visible or turning his or her back while calling the subject). When looking at the test situation in this way, it is perhaps not so surprising that dogs and wolves followed the command when hearing it in a familiar situation, as compared to hearing it as part of a novel context. In sum, we argue that Udell and colleagues' conditions using familiar occluders (or turning their back to the animals) were not adequate to shed light on the perspective-taking skills of dogs and wolves. Instead, these data reflect that the previous experiences of the animals influenced their obedience to a familiar command, as would be expected.

We must disagree, however, with Udell et al.'s (in press) conclusion that experience with a specific occluder is necessary for dogs to succeed in this task. On the contrary, we believe that Udell and her colleagues have found evidence for perspective taking in dogs, in the sense that pet dogs are capable of generalizing the use of the visibility of human eyes as a cue for attentiveness to novel situations. When tested indoors, already in Experiment 1, pet dogs preferably approached the human partner who had a bucket on her shoulder instead of the partner who had the bucket on her head, suggesting that dogs can differentiate between the attentional states of others if they are tested in an undisturbed environment, as has been demonstrated previously in several other studies (Call, Bräuer, Kaminski \& Tomasello, 2003; Gácsi et al., 2004; Schwab \& Huber, 2006; Virányi et al., 2004). Similarly, when tested outside in Experiment 2, they also differentiated between these two partners. The dogs readily learned to preferentially approach the attentive person, but mostly failed to learn to approach the inattentive person. Since pet dogs are hardly ever commanded by people wearing buckets on either their head or shoulder, differentiating between these two partners cannot be explained by the dog's earlier experiences with such situations. Dogs, however, may use their earlier experiences with comparable situations (e.g., when a book is occluding the eyes) to learn about and/or understand the significance of the visibility of their partners' eyes when trying to engage in communication, 
and thus appear to generalize their previously acquired knowledge to a novel context. Udell and her colleagues discuss this interpretation but then reject it, by offering the alternative that the differential learning speeds of the two groups in Experiment 2 can be explained by the resistance of the blind group (those dogs who were repeatedly rewarded for approaching the inattentive partner) to reverse a previously rewarded response. Unfortunately, this argument does not take into account that in Experiment 1 the corresponding group of subjects showed no preference for the attentive partner, and thus, there was no preference that could be reversed, rendering their alternative explanation invalid. Without training, the dogs approached the attentive and inattentive partners with equal frequency, showing that the animals' previous reinforcement experience did not differ with respect to these two specific stimuli (a person calling the subject with a bucket either on her shoulder or on her head). Consequently, in order to explain the differential learning speeds of the two groups in Experiment 2, the dogs must have experienced reinforcement in similar, but not identical, situations that led to the observed performance of the dogs. Pet dogs can experience on a daily basis that it is easier to communicate with humans whose eyes are visible, in contrast to humans whose eyes are covered. In our view, these experiences could be generalized to the novel bucket condition and might have led to the reluctance of $\operatorname{dogs}$ to learn to approach the blind experimenter in Experiment 2. Dogs might have made the same generalization spontaneously when tested inside in Experiment 1, but been too distracted when tested outside.

Finally, we disagree with the authors' conclusion that "grey wolves (Canis lupus) ... are also sensitive to human attentional state" (p. xxx).[COMP: Insert pg no. when available] The wolves in Experiment 1 preferentially approached the person facing them in contrast to the partner who turned her back towards them. However, it is not clear (from either the text or the pictures) whether the hands of the two experimenters offering the food were similarly visible. If the hand of the partner turning her back to the subjects was less exposed than the hand of the seer, it is possible that the wolves preferably approached the more visible hand, as has also been demonstrated in chimpanzees (Kaminski, Call \& Tomasello, 2004). If the two hands were similarly visible to the subjects, preference for the facing person could be explained by the training history of the wolves with the "Come!" command (see earlier in this commentary). Beyond this, the only results suggesting that wolves differentiated between an attentive and an inattentive partner is that in Experiment 2, 2 of 4 wolves learnt to approach the seeing partner, whereas none of the other 4 wolves could be trained to approach the blind partner within 20 trials. These 8 wolves, however, had also participated in Experiment 1. The 4 wolves that were trained to approach the seer had acquired the lowest scores in Experiment 1, while the best-performing 4 wolves were trained to approach the blind partner in Experiment 2. This means that the 4 wolves in the blind group had to reverse their response learned in Experiment 1 to be successful in Experiment 2, which is quite challenging for any animal (Elgier, Jakovcevic, Mustaca \& Bentosela, 2009; Rajalakshmi \& Jeeves, 1965). The animals tested in the seeing group, however, had had no preferential response in Experiment 1, but were further reinforced for the same response as before, facilitating learning. This difference in the previous experiences of the two groups can explain the marginal differences they displayed in Experiment 2.

Consequently, we conclude that at present there is no evidence that wolves are sensitive to the attentiveness of humans. Though, based on their social life and sensitivity to others' gaze direction (Range \& Virányi, 2011), it is feasible to assume that wolves pay attention to the visibility of others' eyes and adjust their communication accordingly, currently there are no data supporting or denying this prediction. Udell et al. (in press), however, have contributed to the growing body of evidence that dogs are sensitive to the attentional states of humans by showing that pet dogs preferentially approached a human partner whose eyes were visible, even if a novel occluder (bucket on the head) was used to cover the eyes of an alternative partner. For this and other reasons, we disagree with their conclusion that the sensitivity of dogs to a human's attentiveness depends on their experiences with a specific occluder covering the human's eyes.

Author note The work is financially supported by Austrian Science Fund (FWF) project P21244-B17, Royal Canin, and the ESF Research Networking Programme "CompCog."

\section{References}

Call, J., Bräuer, J., Kaminski, J., \& Tomasello, M. (2003). Domestic dogs (Canis familiaris) are sensitive to the attentional state of humans. Journal of Comparative Psychology, 117, 257-263. doi:10.1037/0735-7036.117.3.257.

Elgier, A. M., Jakovcevic, A., Mustaca, A. E., \& Bentosela, M. (2009). Learning and owner-stranger effects on interspecific communication in domestic dogs (Canis familiaris). Behavioural Processes, 81, 44-49. doi:10.1016/j.beproc.2008.12.023.

Gácsi, M., Miklósi, Á., Varga, O., Topál, J., \& Csányi, V. (2004). Are readers of our face readers of our minds? Dogs (Canis familiaris) show situation-dependent recognition of human's attention. Animal Cognition, 7, 144-153. doi:10.1007/s10071003-0205-8

Kaminski, J., Call, J., \& Tomasello, M. (2004). Body orientation and face orientation: Two factors controlling apes' begging behavior 
from humans. Animal Cognition, 7, 216-223. doi:10.1007/ s10071-004-0214-2.

Povinelli, D. J., \& Eddy, T. J. (1996). What young chimpanzees know about seeing. Monographs of the Society for Research in Child Development, 61(3, Serial No. 247), 1-189.

Rajalakshmi, R., \& Jeeves, M. A. (1965). The relative difficulty of reversal learning (reversal index) as a basis of behavioural comparisons. Animal Behaviour, 13, 203-211. doi:10.1016/0003-3472(65)90035-7.

Range, F., \& Virányi, Z. (2011). Development of gaze following abilities in wolves (Canis lupus). PloS One, 6, e16888. doi:10.1371/journal.pone.0016888.

Schwab, C., \& Huber, L. (2006). Obey or not obey? Dogs (Canis familiaris) behave differently in response to attentional states of their owners. Journal of Comparative Psychology, 120, 169-175. doi:10.1037/0735-7036.120.3.169.
Theall, L. A., \& Povinelli, D. J. (1999). Do chimpanzees tailor their gestural signals to fit the attentional states of others? Animal Cognition, 2, 207-214. doi:10.1007/s100710050041.

Udell, M. A., Dorey, N. R., \& Wynne, C. D. (in press). Can your dog read your mind? Understanding the causes of canine perspective taking. Learning \& Behavior.

Virányi, Z., Range, F., \& Huber, L. (2009). Attentiveness toward others and social learning in domestic dogs. In L. S. RöskaHardy \& E. M. Neumann-Held (Eds.), Learning from animals? Examining the nature of human uniqueness (pp. 141-153). New York: Psychology Press.

Virányi, Z., Topál, J., Gácsi, M., Miklósi, A., \& Csányi, V. (2004). Dogs respond appropriately to cues of humans' attentional focus. Behavioural Processes, 66, 161-172. doi:10.1016/j.beproc. 2004.01.012. 